\title{
Morphology and phenotype of peripheral erythrocytes of fish: A rapid screening of images by using software
}

\author{
Soumendra Nath Talapatra ${ }^{1 \mathrm{a \#} *}$, Priyadarshini Mitra ${ }^{2 \mathrm{b \#}}$ \\ and Snehasikta Swarnakar ${ }^{3 \mathrm{c}}$
}

${ }^{1}$ Career Advancement Solutions, H2-120A/New, Benir Pole Road Maheshtala, Kolkata - 700141, India

${ }^{2}$ Career Advancement Solutions, H2-120A/New, Benir Pole Road Maheshtala, Kolkata - 700141, India

${ }^{3} \mathrm{CSIR}$-Indian Institute of Chemical Biology

Division of Cancer Biology \& Inflammatory Disorder

4, Raja S. C. Mallick Road, Jadvapur,

Kolkata - 700032, India

aecologylive@yahoo.co.in, b priyadarshinimitra.in@gmail.com, ${ }^{\mathrm{c}}$ sikta@iicb.res.in
\#Equal contribution as first author

${ }^{*}$ Corresponding author: Dr. Soumendra Nath Talapatra, Chief Scientist, H2 - 120A/New, Benir Pole Road, Kolkata 700141. phone: +919831008689, email: ecologylive@yahoo.co.in

Keywords: Peripheral fish erythrocytes, Erythrocytes image, Morphological alteration, Image analysis software, Phenotype and image automation, CellProfiler software

\begin{abstract}
Many information of biological study as stained cells analysis under microscope cannot be obtained rich information like detail morphology, shape, size, proper intensity etc. but image analysis software can easily be detected all these parameters within short duration. The cells types can be yeast cells to mammalian cells. An attempt has been made to detect cellular abnormalities from an image of metronidazole (MTZ) treated compared to control images of peripheral erythrocytes of fish by using non-commercial, open-source, CellProfiler (CP) image analysis software (Ver. 2.1.0). The comparative results were obtained after analysis the software. In conclusion, this image based screening of Giemsa stained fish erythrocytes can be a suitable tool in biological research for primary toxicity prediction at DNA level alongwith cellular phenotypes. Moreover, still suggestions are needed in relation to accuracy of present analysis for Giemsa stained fish erythrocytes because previous works have been carried out images of cells with fluorescence dye.
\end{abstract}

\section{INTRODUCTION}

The cells analysis with different stains under microscope is a technique where different cellular morphology can be identified. It has been well established by several researchers from decade [1-4]. But this analysis may be time consuming by large scale screening, visual error by individual eye estimation, sometimes missing of cellular features as subtle change undistinguishable by eye visually and also requires proper expertise to recognize cellular features. To minimize time, visual error, proper identification of cellular features etc. cell analysis with algorithm based software has been recommended by researchers [5-11] however, the proper set up may be tedious to incorporate the input data in the software [11].

Generally cell image analysis has been showed accurate identification and measurement of all types of cellular features by automatic analysis of certain phenotypes through software, previously studied by many researchers $[6,8,11,12-24]$. It was also known that machine learning methods, which have been selected and combined multiple features for automated cell classification and used to detect many cellular phenotypes [12, 13, 15, 17, 18-25].

According to Carpenter et al. [6], the easy screening image analysis software, CellProfiler (CP) is freely available (non-commercial) image analysis software, can capable of handling 100 nos. of 
images of any cell types like yeast colony to mammalian cells [11]. CP software helps to detect the biological information quickly with statistical power and the simple cellular morphology viz. cell count, shape, size, etc. alongwith protein levels in individual cell as well as complex morphological parameters like cell/organelle shape or subcellular patterns of DNA or protein from stained images. Many works have been carried out on fluorescent stained cells but no one has been attempted before Giemsa stained image analysis from erythrocytes of fish to detect rich information from stained cells by using CP.

The present study attempts to detect cells morphology and phenotype from Giemsa stained images of micronucleated erythrocytes compared with normal erythrocytes by using CP image analysis software because several features cannot be identified only under microscope when visualize stained cells.

\section{MATERIALS AND METHODS}

\subsection{Selection of software and images as input}

Images of Giemsa stained normal and micronucleated peripheral erythrocytes were processed by using CellProfiler or CP (Version 2.1.0), this software was downloaded from the website as http://www.cellprofiler.org/download.shtml. The input data were incorporated in the present software by trial and error method with the help of CP manual published through the mentioned link (http://www.cellprofiler.org/linked_files/Documentation/cp2.1.1_manual_6c2d896.pdf) for detail description for users [6]. The CP software interface is depicted on the basis of selected input and analysis modules for the present study (Fig. 1).

The two images were taken from previous research work on metronidazole (MTZ) induced genotoxicity in peripheral erythrocytes of fish [26]. In the present study, the images were selected two types of cells and nuclei deformities as micronucleated and normal erythrocytes of fish. Both images were incorporated and analysed in the software separately as per selected input and analysis modules. These images were obtained through CP are depicted in Fig 2 and 2a.

\subsection{Measurement of cellular features}

In each image, the area, shape, intensity, and texture was measured as per appropriate input and data were found in .csv extension. It was well established that CP can measure a variety and number of features for individual identified cell or compartmentalize at subcellular level included area, shape, intensity and texture of objects. These are common features, which described by researchers $[6,11$, $13,27]$ but the complex measurements like zernike shape features (shape descriptors of objects in image), Haralick and Gabor texture features have also been studied before by other researchers, which are found in detail in the CP manual [12, 28-31].

In the present study, the measurement of both images were considered separately as input. For individual parameter viz. apply threshold, correct illumination apply, crop image, enhance edges, mask and morph image, identify primary, secondary and tertiary objects, mask objects, intensity, size and shape, radial distribution of objects, cells, cytoplasms and nuclei location centre from $\mathrm{X}$ axis were selected in the software and analysed all the data (Fig. 1). The data were obtained through images and various computerized simulation processes and saved as .csv file.

\subsection{Image processing and data gathering for rich information in cells}

According to Carpenter et al. [6], the cellular analysis were done by compartmentalize morphology of cells, object validitied by green, yellow and red colours, which identified nuclei, cytoplasms and cells boundaries, location comparison of nuclei, cytoplasms and cells in each image, total intensities were compared for nuclei, cytoplasms and cells. The features were studied primarily related to object shape of nuclei, cytoplasms and cells, descriptor based zernike moments 0 order to 9 order and total nos. of pixels. The features were compared for nuclei, cytoplasms and cells for each image separately. 


\section{RESULTS}

Images of Giemsa stained normal (control) and micronucleated (experiment) peripheral erythrocytes were inserted in the $\mathrm{CP}$ software separately alongwith setting of all the selected necessary parameters as input and analysed data (Fig. 1). The images were obtained through CP in measured position after incorporated in the software (Fig. 2 and 2a). In case of threshold application, it was observed the threshold value of 0.08 and 0.19 for control and experiment images respectively and the images after thresholding are depicted in Fig. 3 and 3a. The output as illumination correction after apply is depicted in Fig. 4 and $4 \mathrm{a}$ for control and experiment respectively. The image crop was applied for both the control and experiment images and the results are depicted in Fig. 5 and 5a. The enhance edge application as peripheral boundary of individual object for the both images were obtained and the results are depicted in Fig. 5 and 5a. The results were obtained after masking and morphing the images for control and experiment and are depicted in Fig. 7 and $7 \mathrm{a}$ and 8 and 8a respectively.

In case of control and experiment primary object data, it was observed that marking of nuclei by outline, the data were obtained 10th pctile diameter (14.3 and 13.4 pixels) while 90th pctile diameter (34.1 and 32.3 pixels) respectively. The results for both types of images as output are depicted in Fig. 9 and 9a. In case of control and experiment secondary object data, it was observed that marking of all the cells and nuclei boundary in individual image, the data were obtained 10th pctile diameter (14.9 and 13.9 pixels) while 90th pctile diameter (36.5 and 36.1 pixels) respectively. The results for both types of images as output are depicted in Fig. 10 and 10a. In case of control and experiment tertiary object data, it was observed that marking of all the nuclei, cells and cytoplasm by separate outline for individual image. The results for both types of images as output are depicted in Fig. 11 and 11a. The masking objects for all the cells and masked nuclei were obtained for control and experiment images separately and are depicted in Fig. 12 and 12a.

The object intensities were obtained of different parameters viz. integrated intensity, integrated intensity edge, center mass intensity $\mathrm{X}$, center mass intensity $\mathrm{Y}$, maximum intensity $\mathrm{X}$ and maximum intensity $\mathrm{Y}$ for cells, cytoplasms and nuclei separately for both control and experiment images, which are expressed by histogram (Fig. 13 and 13a). Lower intensity values were observed in experiment when compared to control image for cells, cytoplasms and nuclei. In case of objects shape and size data, it was observed that in experiment image the area, perimeter and minimum and maximum ferret diameter of cells, cytoplasm and nuclei were showed lower value except center $\mathrm{X}$ and Y (higher value), when compared to control value, histogram illustrated in Fig. 14 and 14a.

In Fig. 15 and 15a, it was observed for cells, cytoplasms and nuclei of control and experiment images separately for zernike moments of order 0 to order 9 . The minimal differences were observed between control and experiment images.

\section{DISCUSSION}

The present study was emphasized on the basis of visually observed peripheral erythrocytes of fish, one is normal (without treatment as control) image and other is micronucleated cells (treated with MTZ) image to screen morphological and phenotype differences after automated analysis through $\mathrm{CP}$, an image based analysis software. This software can screen easily of $2 \mathrm{D}$ images and detect different parameters of cellular phenotype viz. size, shape, intensity, texture etc. through high throughput way [6]. According to their concept and software manual, the present study was dealt with Giemsa stained nuclear abnormalities cells compared with control cells. The data obtained after the analysis of CP software that cannot be possible to study cellular morphology visualization only under microscope.

CP has already been used by several laboratories in the globe and researchers are studying a variety of biological processes in different cell types and organisms, viz. yeast colony, Drosophila melanogaster (S2R+ cells, epithelial tissues), various human samples namely TOV21G, prostate gland tissue, stem cells of mesenchymal origin, H1299 lung cancer cell lines, mouse samples such 
as NIH/3T3 cell lines, neural precursor cells of embryos, cells from lung tissue, germ cells and also H9c2 cell lines of rat model [6, 11, 16, 32-36].

It was reported by Lamprecht et al. [7] that CP has also modified for the measurement of yeast colonies, yeast growth patches, wounds healing assays and tumours quantification. But in the present study, Giemsa stained fish blood cells may provide cellular features through CP analysis and also informed cellular deformities with special reference to nuclei abnormalities by object intensity, shape and size and pixel size of primary (nuclei) and secondary (cells) object data.

According to Khotanzad and Hong, [37], Suk et al. [38] and [39], zerrnike moment is a viable shape descriptors to screen accuracy and this parameter could be ideal for applications when little data is provided in algorithm. The present results were showed very minimal difference between control and experiment images, which is expressed in histogram (Fig. 14 and 14a) while other parameters such as object intensity and object shape and size were observed a good differences in experiment when compared to control images (Fig. 12 and 12a and 13 and 13a). The present study with Giemsa stained erythrocytes whether worked properly by using this present software still unclear in many aspects. It is required necessary suggestions by other researchers, those who have been investigated and/or working with fluorescence stained cells.

\section{CONCLUSION}

In conclusion, present study is an approach to screen images of Giemsa stained peripheral erythrocytes of fish to know differences of MTZ treated micronucleated cells compared to control cells on the basis of object identification, shape, size, zernike moment by using CP software, an image based analysis software developed by Carpenter et al. [6]. However, the study has been reported majorly in fluorescence stained images except the study of yeast colony [11]. This study can be a suitable tool for biological research for extraction of rich information in image for nuclei stained with DNA binding non-fluorescence dye and to know easily cell deformities with the special reference to the change of objects intensity, shape, size and area of cells, nuclei and cytoplasm after the exposure of toxins.

In other words, also necessary suggestions are required to know how far the present work is done accurately for Giemsa stained cells because previous works have been carried out with images of fluorescence dye in different cell types except yeast colony. 


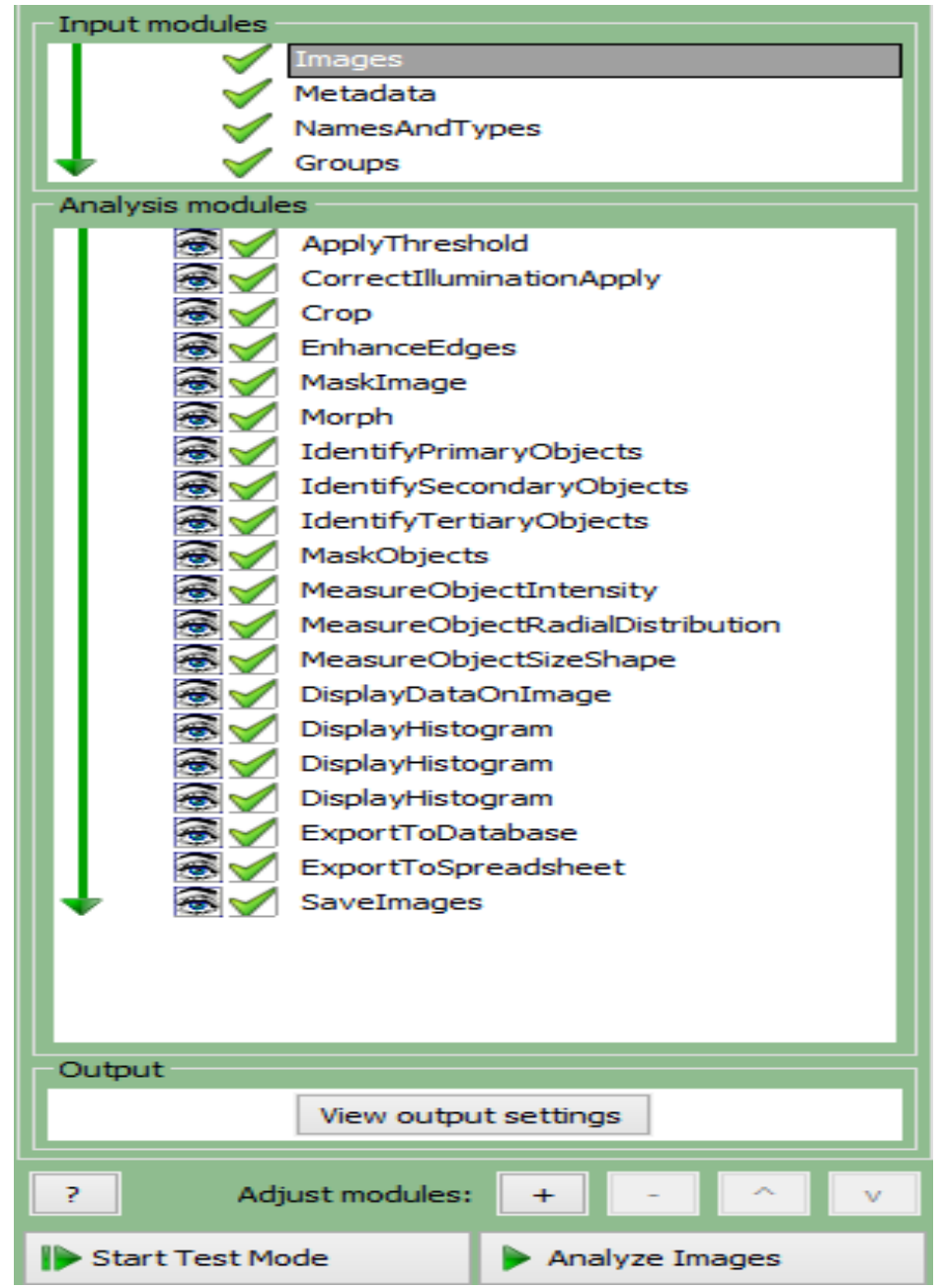

Fig. 1 CP interface of different modules selected for control and experiment images

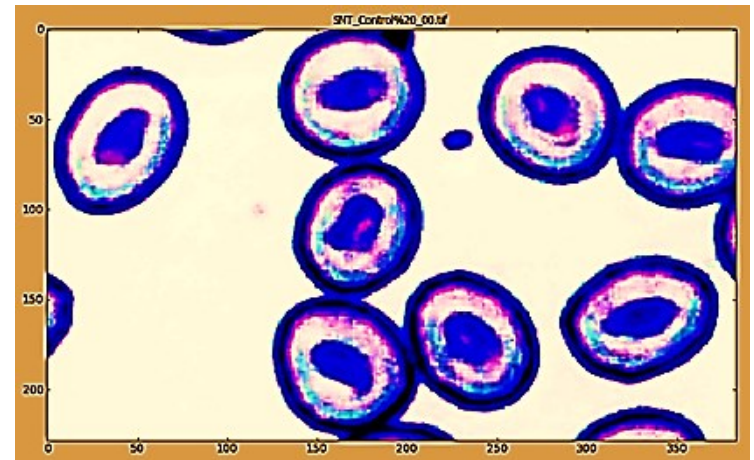

Fig. 2 Original image of control obtaining through CP software

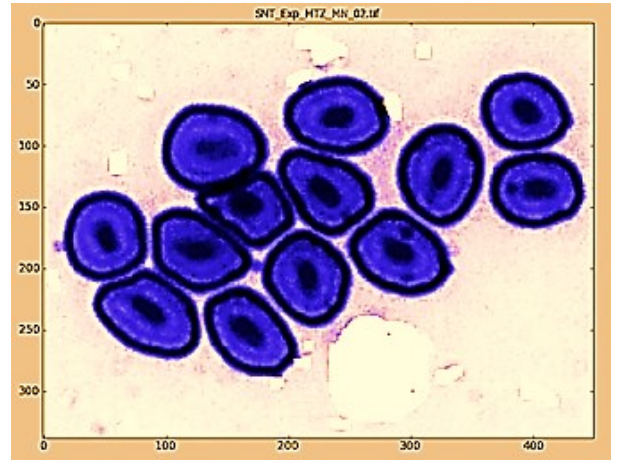

Fig. 2a Original image of experiment obtaining through $\mathrm{CP}$ software

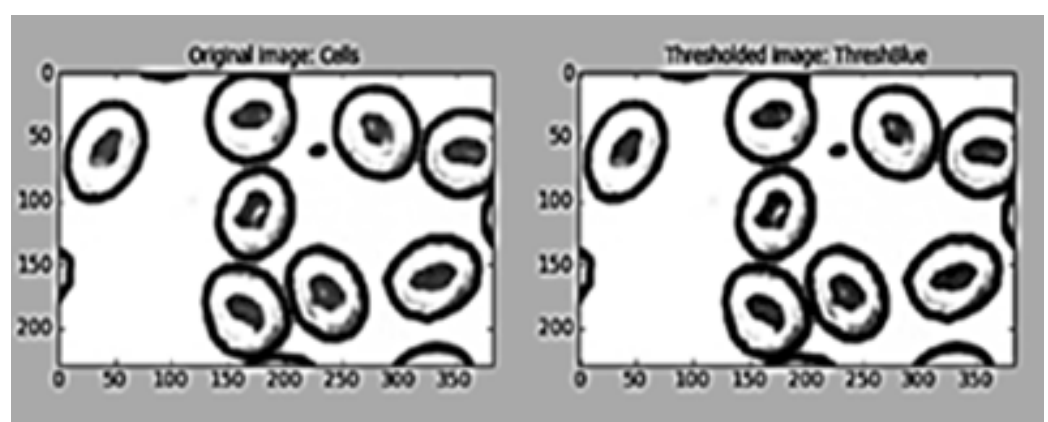

Fig. 3 Threshold apply control image output 


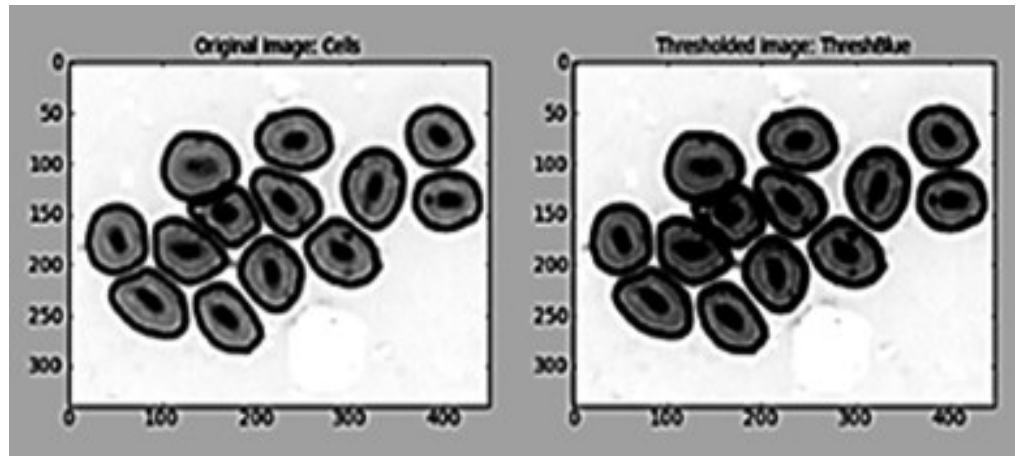

Fig. 3a Threshold apply experiment image output

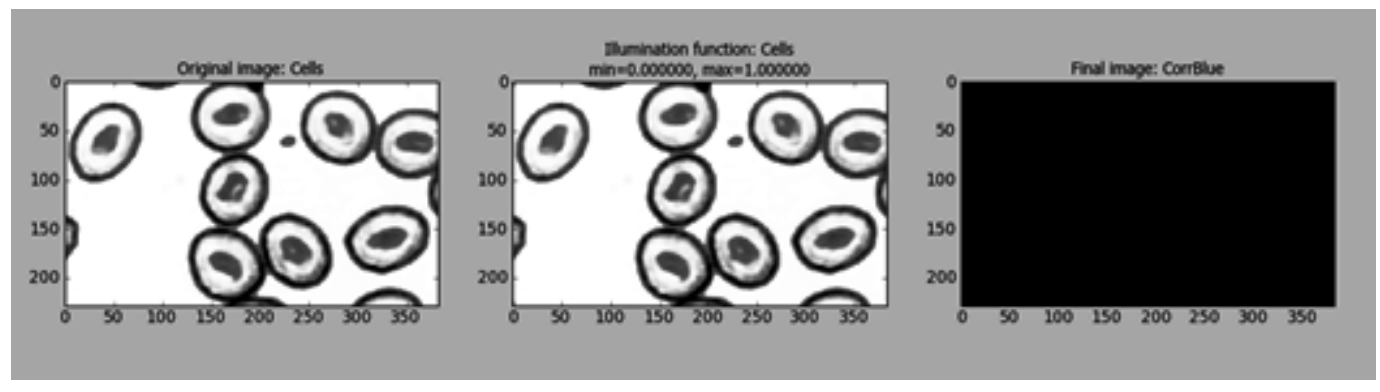

Fig. 4 Correct Illumination apply control image output

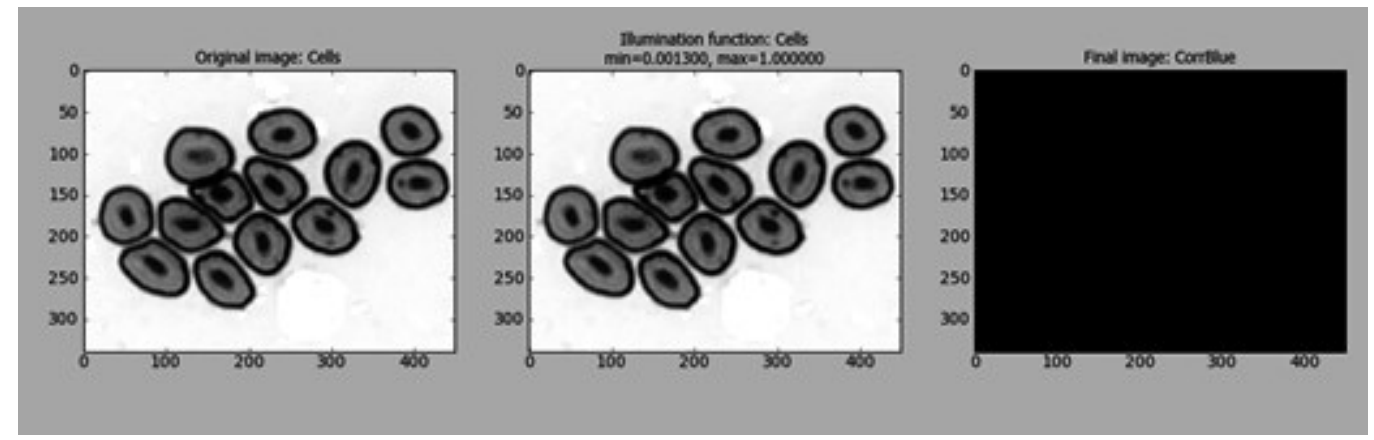

Fig. 4a Correct Illumination apply experiment image output

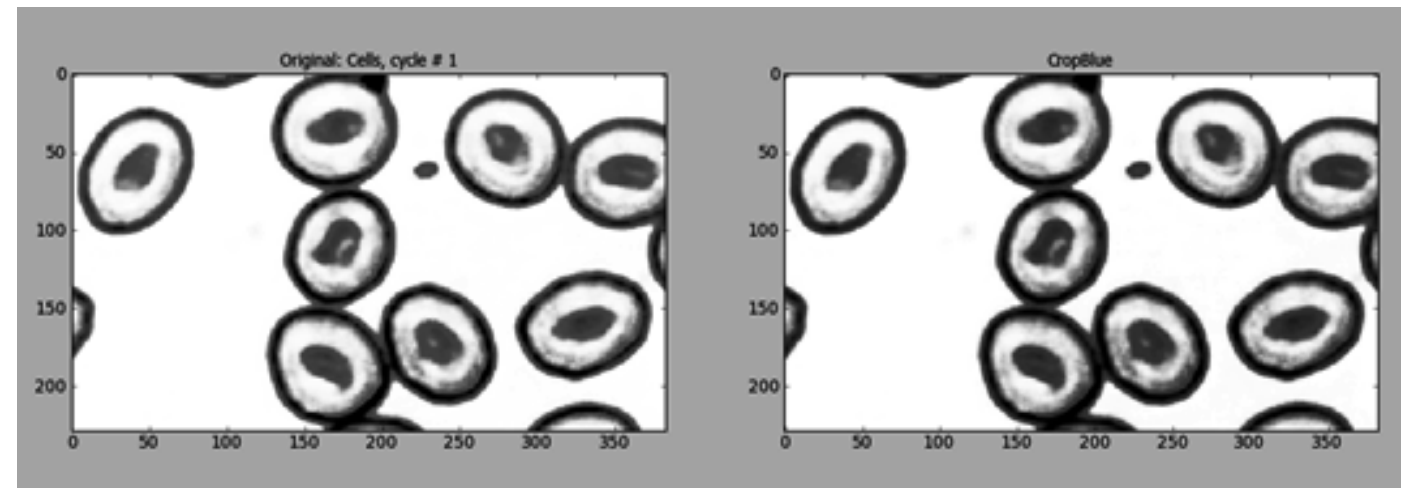

Fig. 5 Crop output of control image 


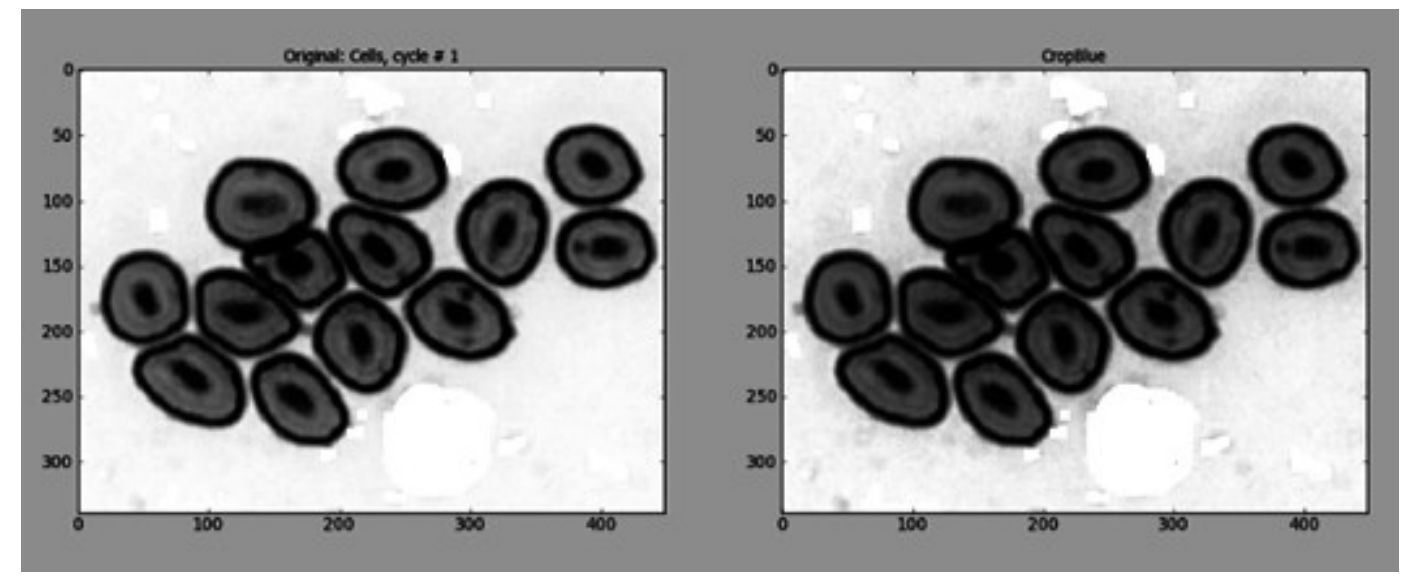

Fig. 5a Crop output of experiment image

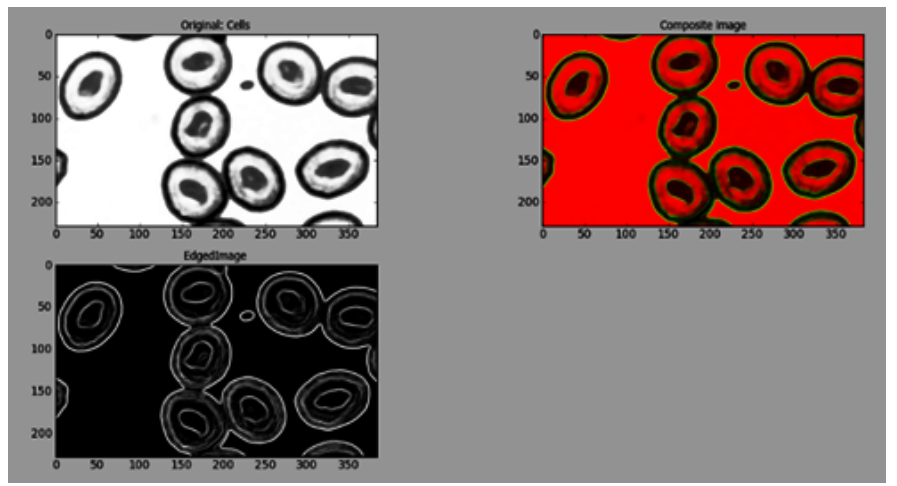

Fig. 6 Enhance edges output of control image

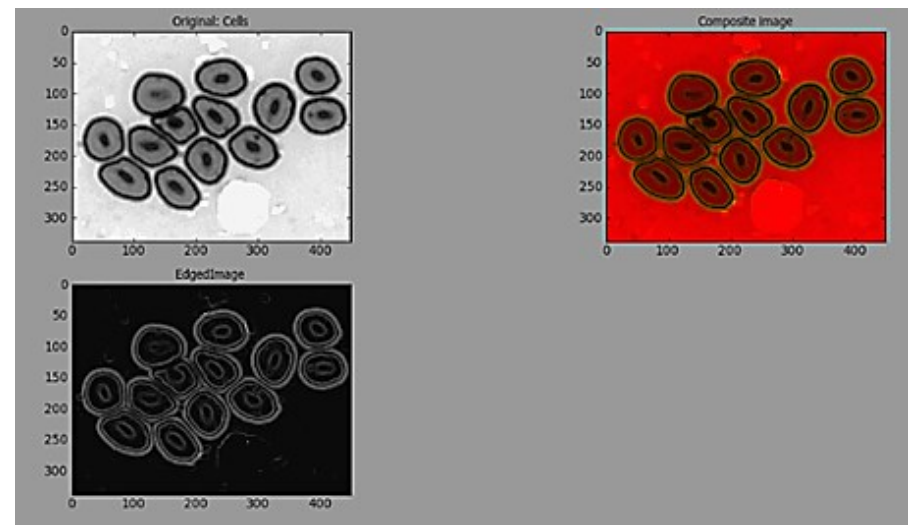

Fig. 6a Enhance edges output of experiment image
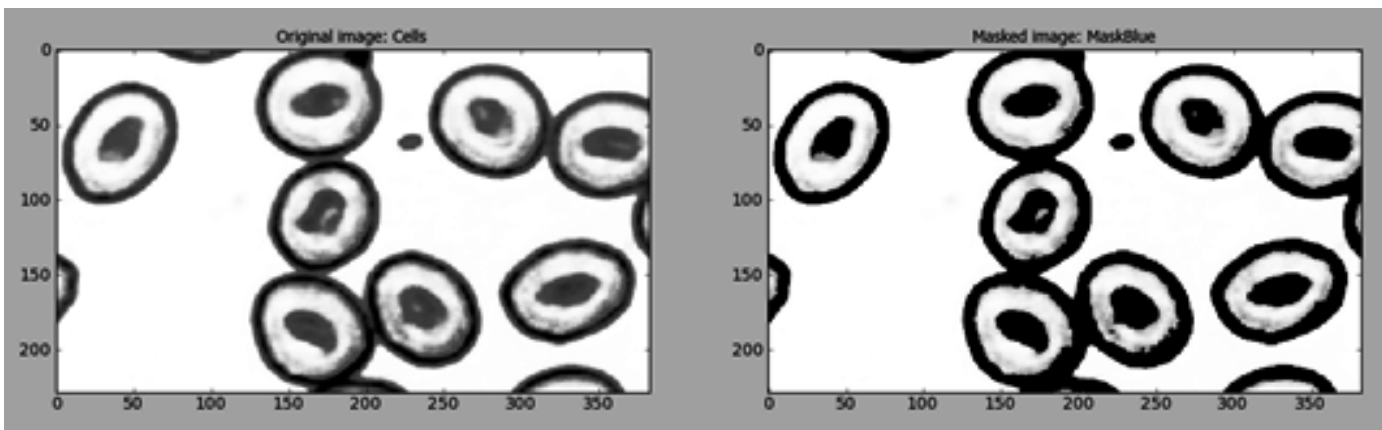

Fig. 7 Mask output of control image 


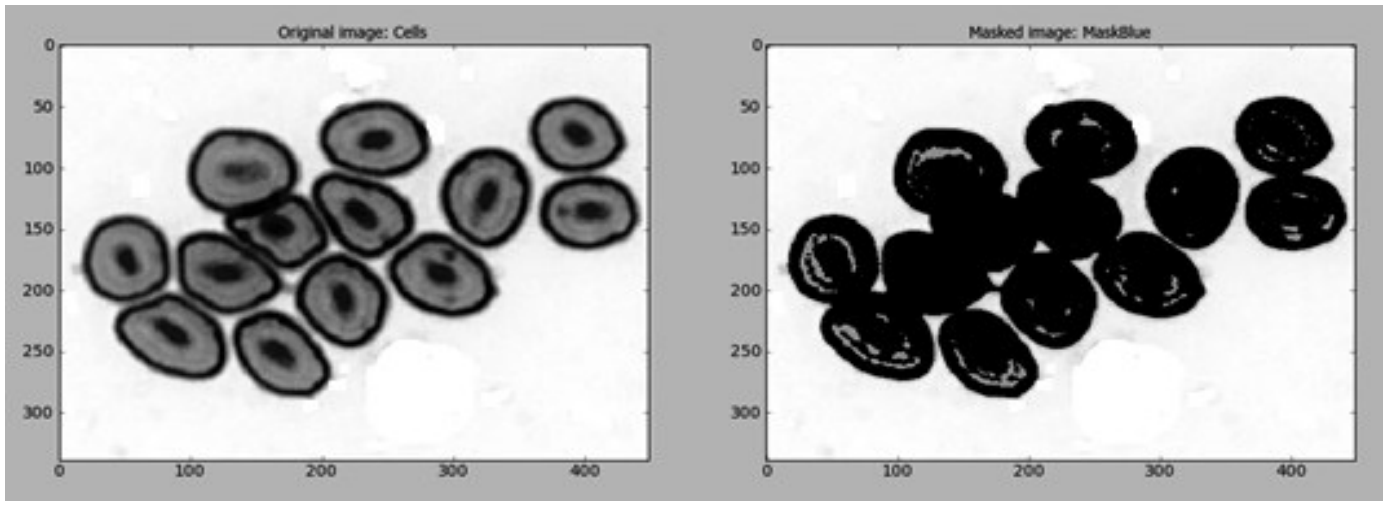

Fig. 7a Mask output of experiment image

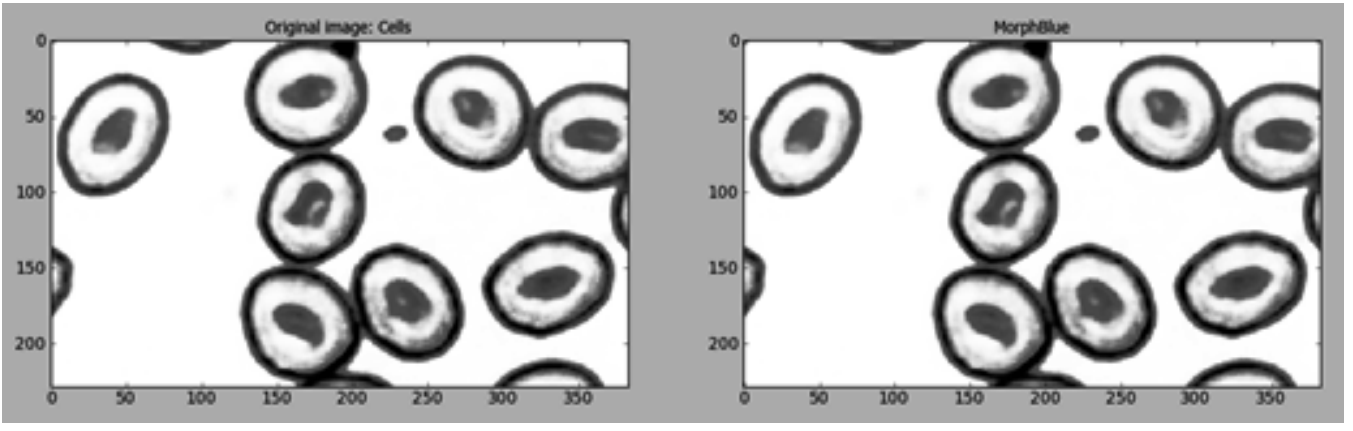

Fig. 8 Morph output of control image

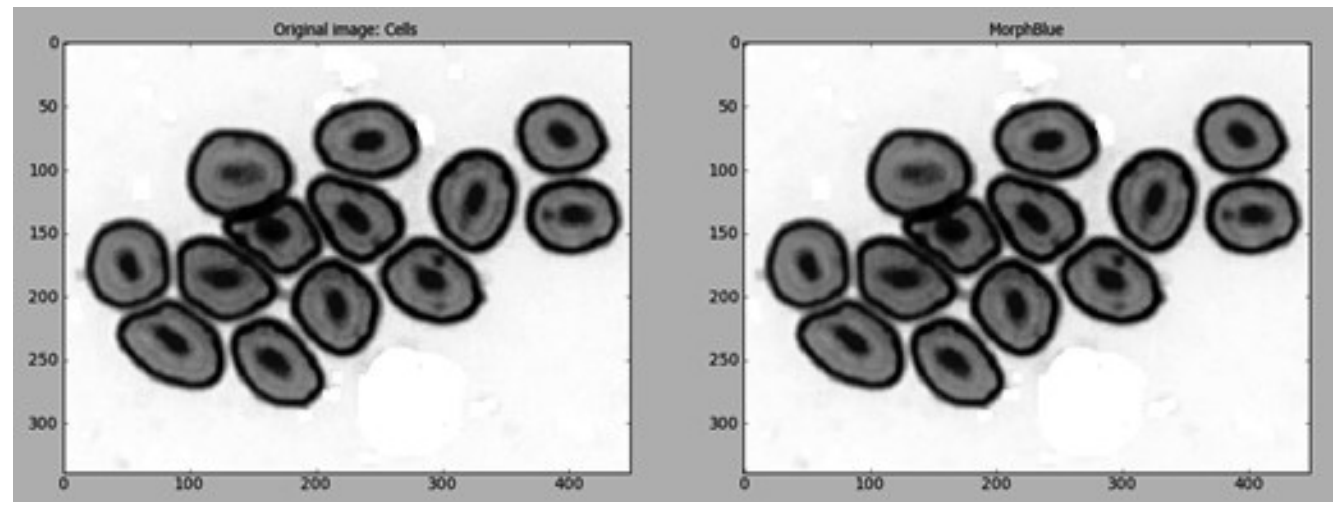

Fig. 8a Morph output of experiment image

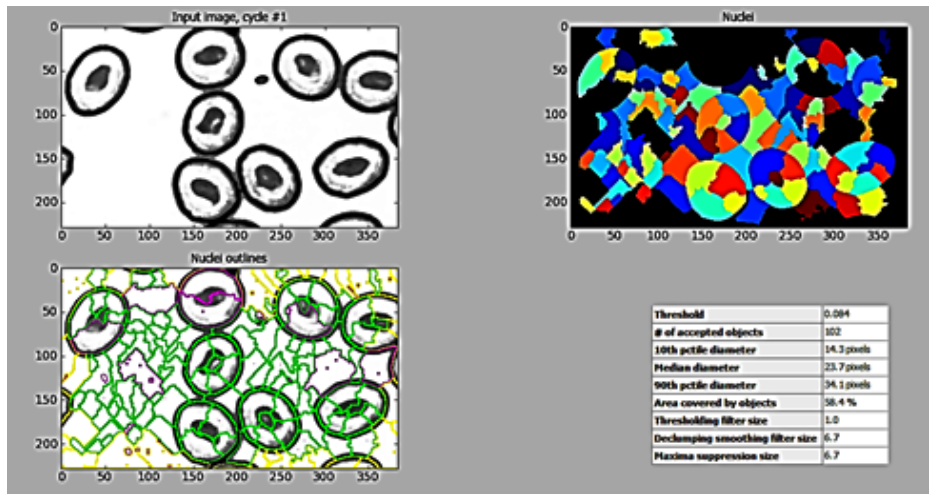

Fig. 9 Primary object output data for control image 


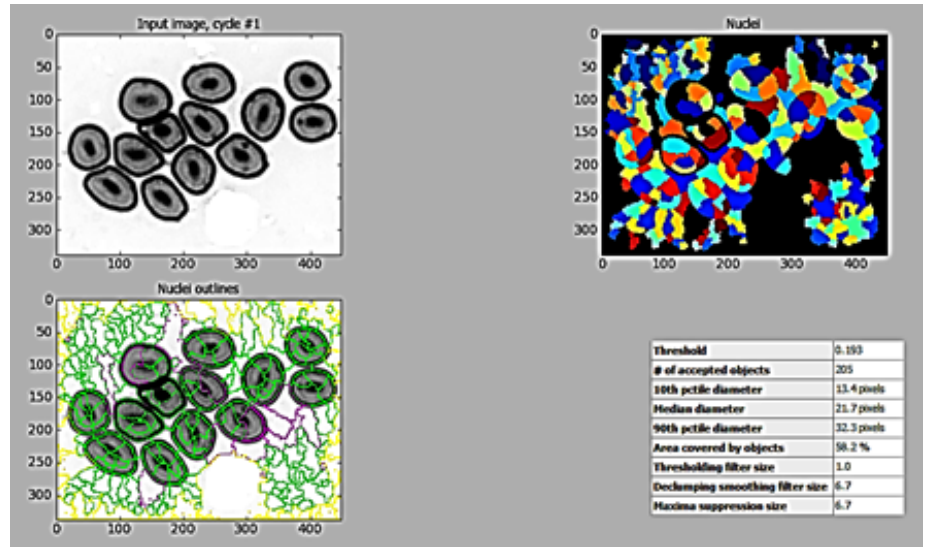

Fig. 9a Primary object output data for experiment image

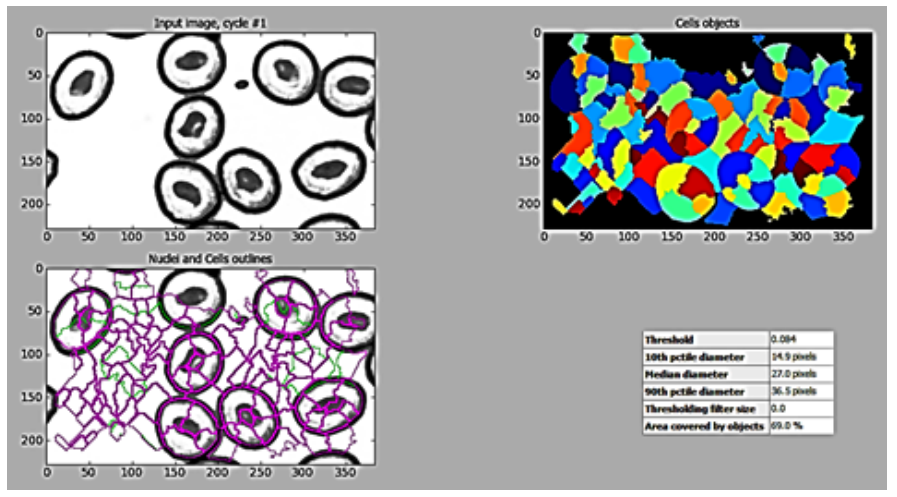

Fig. 10 Secondary object output data for control image

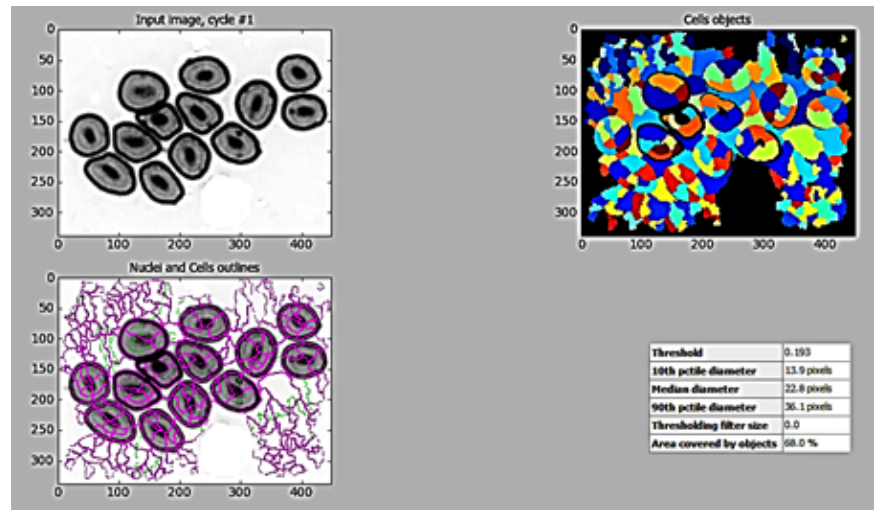

Fig. 10a Secondary object output data for experiment image

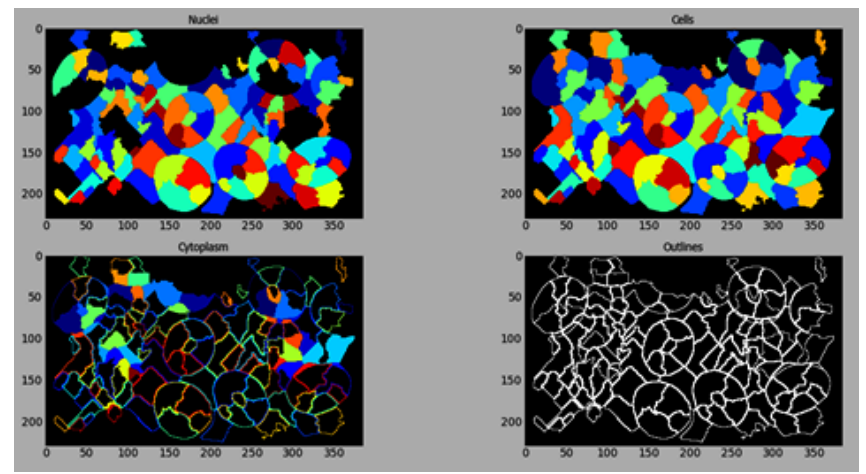

Fig. 11 Tertiary object output data for control image 


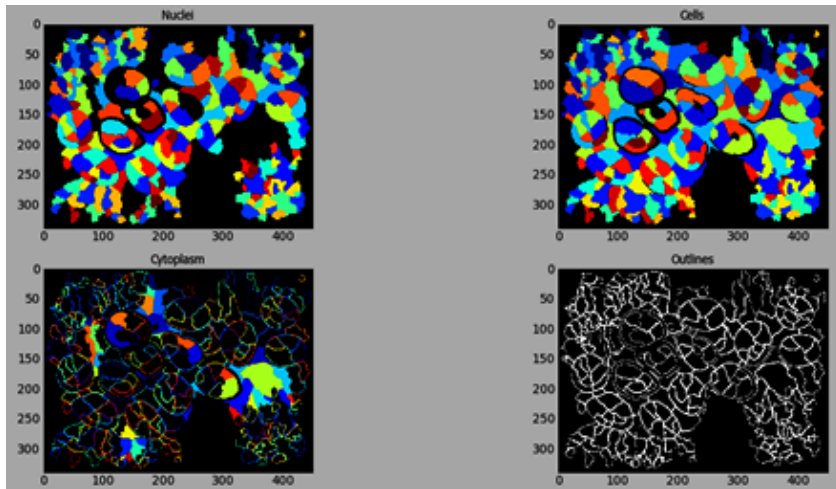

Fig. 11a Tertiary object output data for experiment image

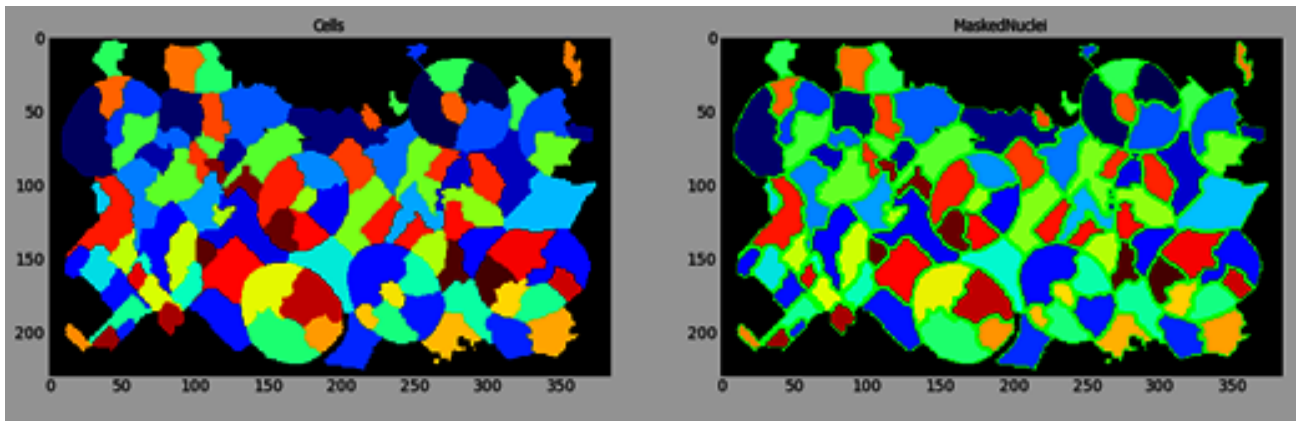

Fig. 12 Mask objects output for control image
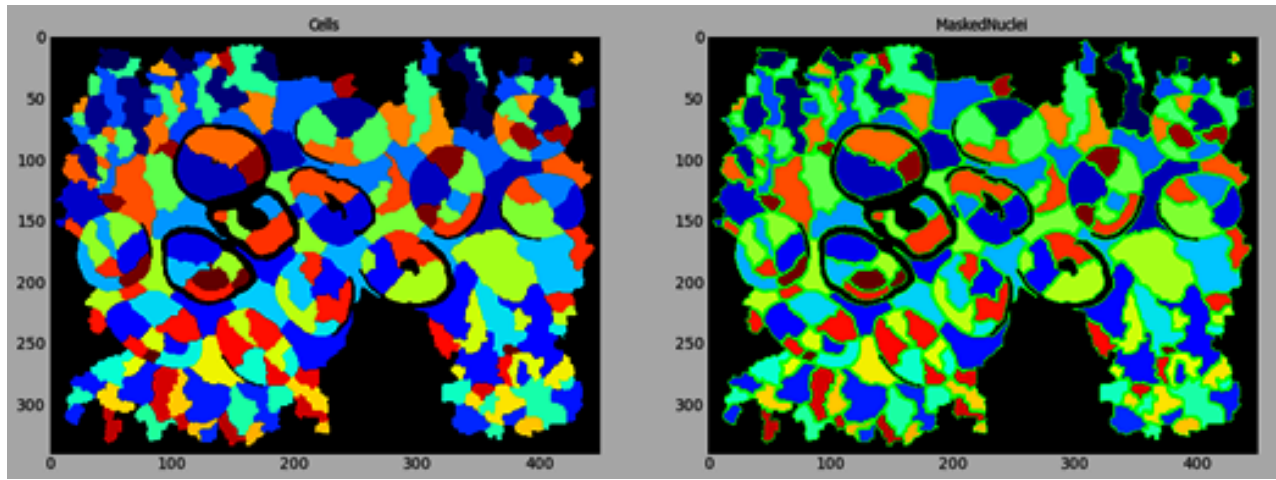

Fig. 12a Mask objects output for experiment image

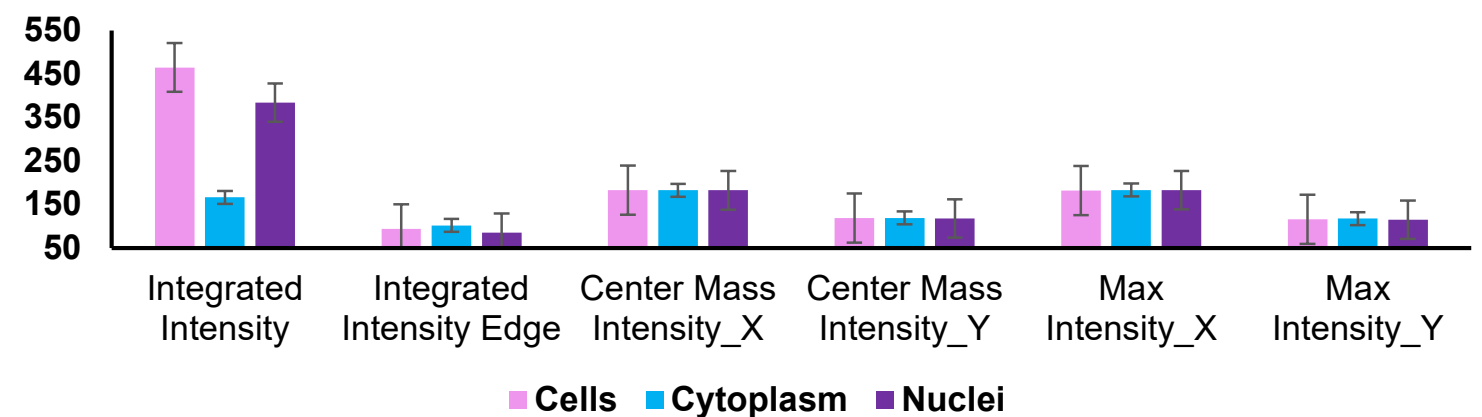

Fig. 13 Histogram of control object intensity data (arbitrary unit) 


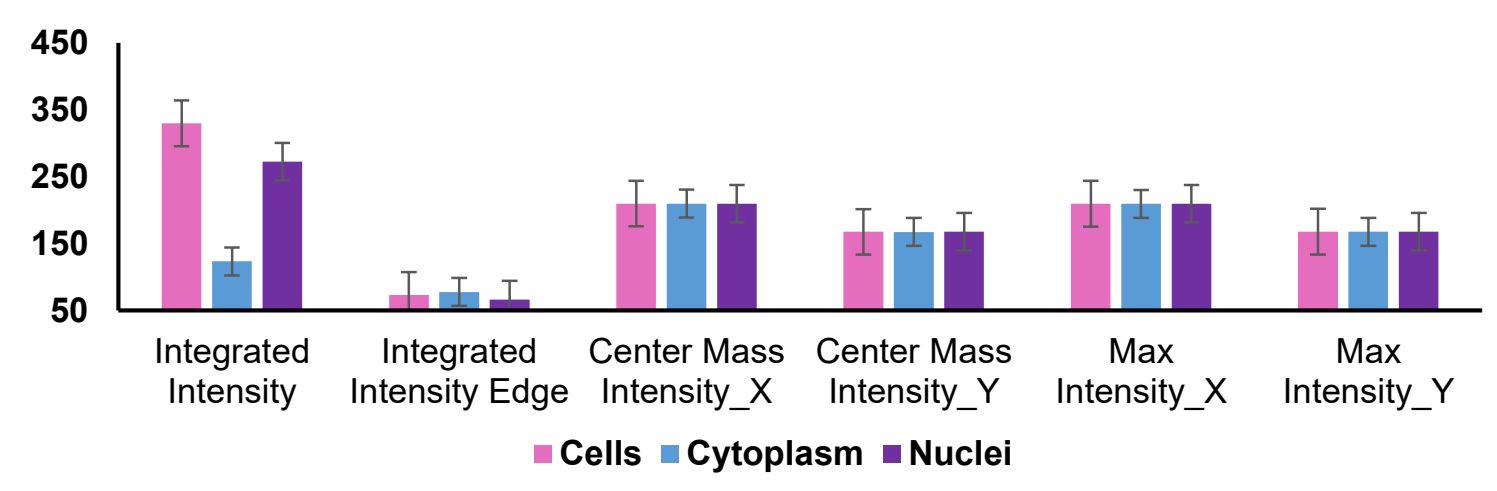

Fig 13a Histogram of experiment object intensity data (arbitrary unit)

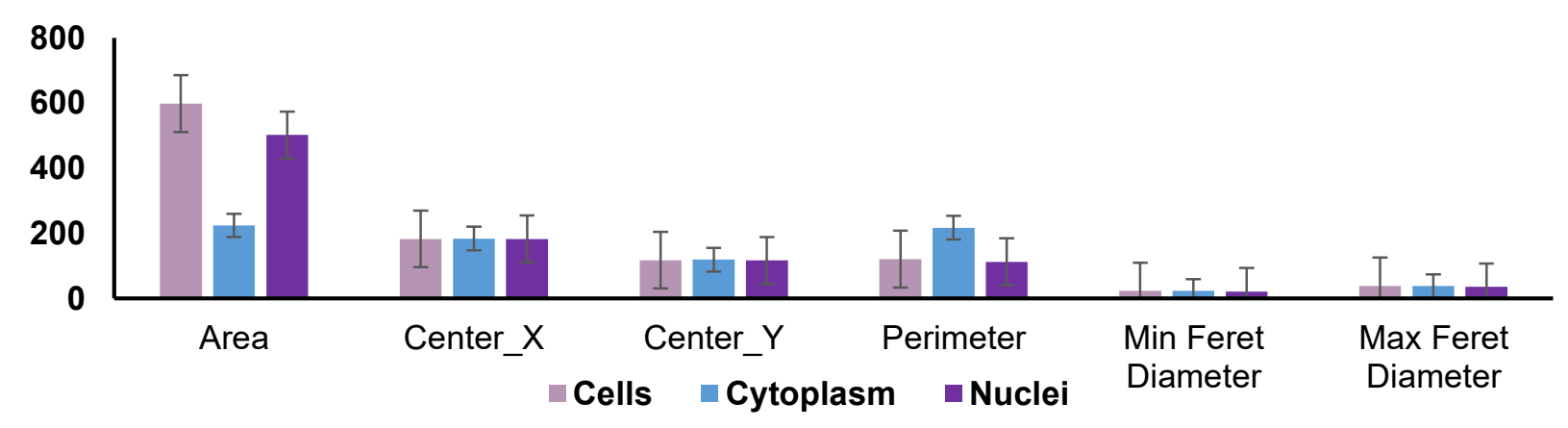

Fig 14 Histogram of control object shape and size data (arbitrary unit)

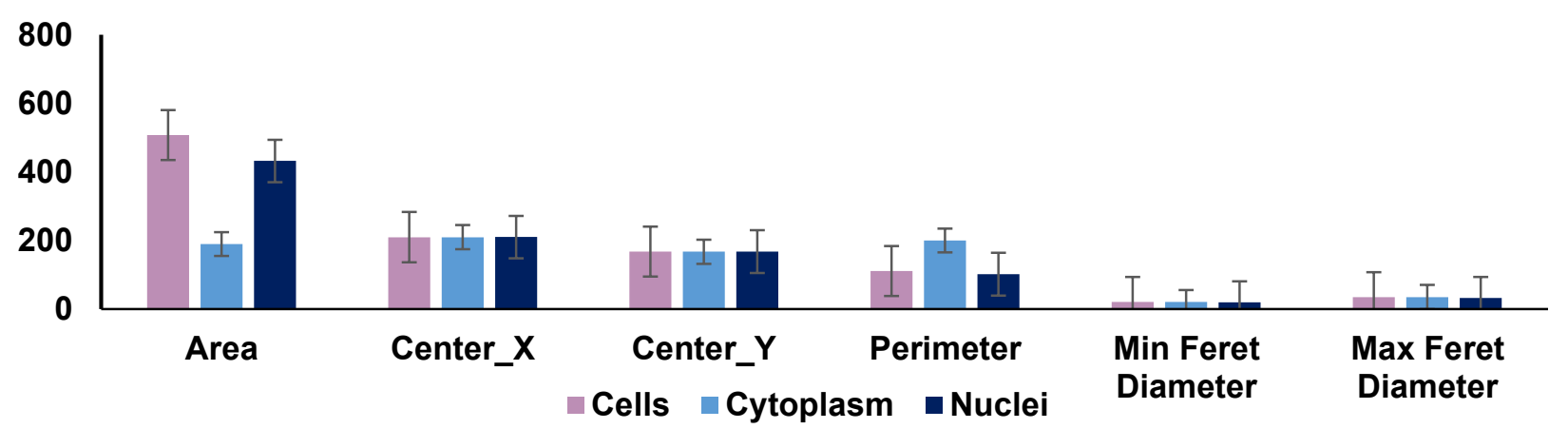

Fig 14a Histogram of experiment object shape and size data (arbitrary unit) 


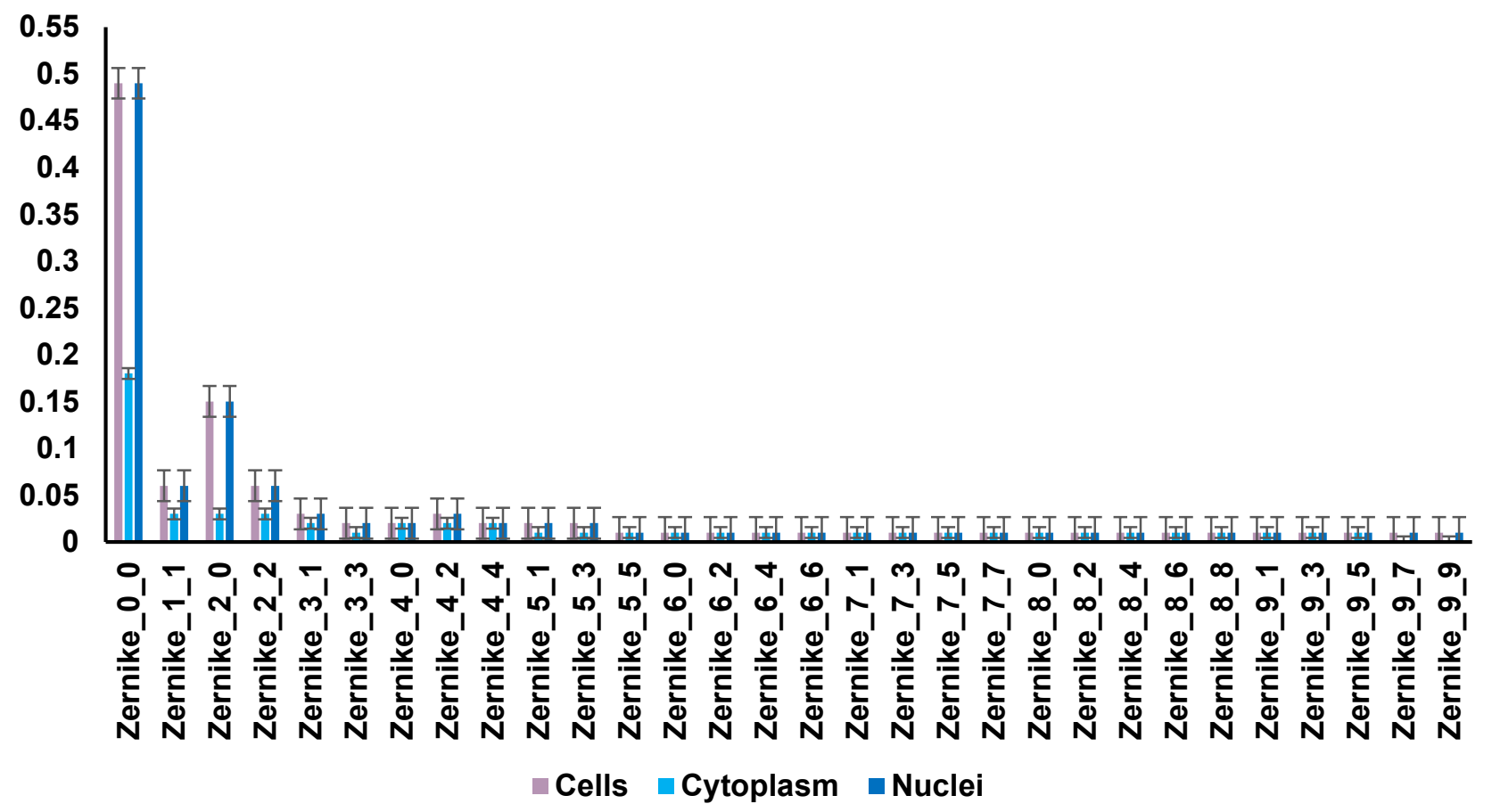

Fig. 15 Histogram of control object zernike moment data (arbitrary unit)

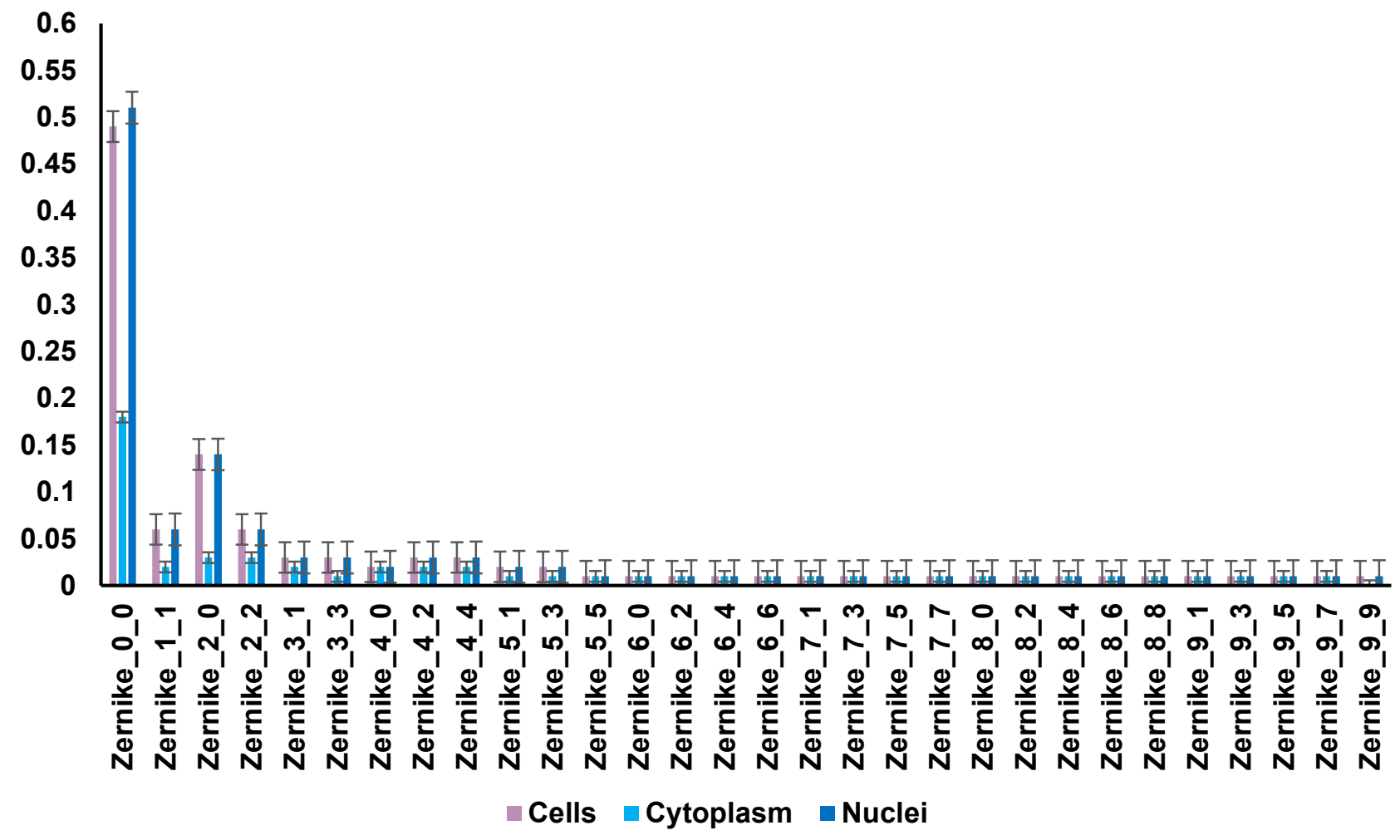

Fig. 15a Histogram of experimental object zernike moment data (arbitrary unit) 


\section{REFERENCES}

[1] J. T. Isaacs, W.B. Isaacs, W.F.J. Feitz, J. Scheres, Establishment and characterization of seven dunning rat prostatic cancer cell lines and their use in developing methods for predicting metastatic abilities of prostatic cancers, Prostate 9 (1986) 261-281.

[2] K.A.Giuliano, R.L. DeBiasio, R.T. Dunlay, A. Gough, J.M. Volosky, J. Zock, G.N. Pavlakis, D.L. Taylor, High-content screening: a new approach to easing key bottlenecks in the drug discovery process, J. Biomol. Screen. 2 (1997) 249-259.

[3] B.M. Rothen-Rutishauser, S. Schurch, B. Haenni, N. Kapp, P. Gehr, Interaction of fine particles and nanoparticles with red blood cells visualized with advanced microscopic techniques, Environ. Sci. Technol. 40 (2006) 4353-4359.

[4] K. Tomankova, H. Kolarova, M. Vujtek, H. Zapletalova, Study of cancer cells used atomic force microscopy. Modern Research and Educational Topics in Microscopy. A. Méndez-Vilas, and J. Díaz, (Eds.). Formatex (2007) pp.23-28.

[5] C. Wahlby, I.M. Sintorn, F. Erlandsson, G. Borgefors, E. Bengtsson, Combining intensity, edge and shape information for 2D and 3D segmentation of cell nuclei in tissue sections, J. Microsc. 215 (2004) 67-76.

[6] A.E. Carpenter, T.R. Jones, M.R. Lamprecht, C. Clarke, I.H. Kang, O. Friman, D.A. Guertin, J.H. Chang, R.A. Lindquist, J. Moffat, P. Golland, D.M. Sabatini, CellProfiler: image analysis software for identifying and quantifying cell phenotypes, Genome Biol. 7 (2006) R100.

[7] M. R. Lamprecht, D.M. Sabatini, A.E. Carpenter, CellProfiler: free, versatile software for automated biological image analysis, Biotechniques 42 (2007) 71-75.

[8] T.R. Jones, A.E. Carpenter, M.R. Lamprecht, J. Moffat, S.J. Silver, J.K. Grenier, B. Adam, A.D. Castoreno, U.S. Eggert, D.E. Root, P. Golland, D.M. Sabatini, Scoring diverse cellular morphologies in image-based screens with iterative feedback and machine learning, Proc. Nat. Acad. Sci. USA 106 (6) (2009) 1826-1831.

[9] V. Ljosa, A.E. Carpenter, Introduction to the quantitative analysis of two-dimensional fluorescence microscopy images for cell-based screening, PLoS Comput. Biol. 5 (12) (2009) e1000603. doi:10.1371/journal.pcbi.1000603.

[10] L. Kamentsky, T.R. Jones, A. Fraser, M.-A. Bray, D.J. Logan, K.L. Madden, V. Ljosa, C. Rueden, K.W. Eliceiri, A.E. Carpenter, Improved structure, function, and compatibility for CellProfiler: Modular high-throughput image analysis software, Bioinformatics 27 (2011) 11791180.

[11] M.-A. Bray, M.S. Vokes, A.E. Carpenter, Using CellProfiler for automatic identification and measurement of biological objects in images, Curr. Protoc. Mol. Biol. 109 (2015) 14.17.1-14.17.13 doi: $10.1002 / 0471142727 . \mathrm{mb} 1417 \mathrm{~s} 109$.

[12] M.V. Boland, M.K. Markey, R.F. Murphy, Automated recognition of patterns characteristic of subcellular structures in fluorescence microscopy images, Cytometry 33 (1998) 366-375.

[13] M.V. Boland, R.F. Murphy, A neural network classifier capable of recognizing the patterns of all major subcellular structures in fluorescence microscope images of HeLa cells, Bioinformatics 17 (2001) 1213-1223.

[14] A.A. Kiger, B. Baum, S. Jones, M.R. Jones, A. Coulson, C. Echeverri, N. Perrimon, A functional genomic analysis of cell morphology using RNA interference, J. Biol. 2 (4) (2003) 27.

[15] M. Tanaka, B. Bateman, D. Rauh, E. Vaisberg, S. Ramachandani, C. Zhang, K.C. Hansen, A.L. Burlingame, J.K. Trautman, K.M. Shokat, C.L. Adams, An unbiased cell morphology-based screen for new, biologically active small molecules, PLoS Biol. 3 (5) (2005) e128. 
[16] J. Moffat, D.A. Grueneberg, X. Yang, S.Y. Kim, A.M. Kloepfer, G. Hinkle, B. Piqani, T. M. Eisenhaure, B. Luo, J.K. Grenier, A.E. Carpenter, S.Y. Foo, S.A. Stewart, B.R. Stockwell, N. Hacohen, W.C. Hahn, E.S. Lander, D.M. Sabatini, D.E. Root, A lentiviral RNAi library for human and mouse genes applied to an arrayed viral high-content screen, Cell 124 (2006) 1283-1298.

[17] B. Neumann, M. Held, U. Liebel, H. Erfle, P. Rogers, R. Pepperkok, J. Ellenberg, Highthroughput RNAi screening by time-lapse imaging of live human cells, Nat. Methods 3 (2006) 385390.

[18] C.L. Adams, V. Kutsyy, D.A. Coleman, G. Cong, A.M. Crompton, A. Elias, D. R. Oestreicher, J.K. Trautman, E. Vaisberg, Compound classification using image-based cellular phenotypes, Methods Enzymol. 414 (2006) 440-468.

[19] X. Chen, R.F. Murphy, Automated interpretation of protein subcellular location patterns," Int. Rev. Cytol. 249 (2006) 193-227.

[20] N. Orlov, J. Johnston, T. Macura, L. Shamir, I. Goldberg, Computer vision for microscopy applications. Vision Systems: Segmentation and Pattern Recognition, eds. G. Obinata, and A. Dutta, I-Tech, Vienna, (2007) pp 221-242.

[21] C. Lin, W. Mak, P. Hong, K. Sepp, N. Perrimon, Intelligent interfaces for mining large-scale RNAi-HCS image databases. IEEE 7th International Conference on Bioinformatics and Biomedical Engineering, IEEE, Washington DC (2007).

[22] L.H. Loo, L.F. Wu, S.J. Altschuler, Image-based multivariate profiling of drug responses from single cells, Nat. Methods 4 (2007) 445-453.

[23] D.W. Young, A. Bender, J. Hoyt, E. McWhinnie, G-W. Chirn, C.Y. Tao, J.A. Tallarico, M. Labow, J.L. Jenkins, T.J. Mitchison, Y. Feng, Integrating high-content screening and ligand-target prediction to identify mechanism of action, Nat. Chem. Biol. 4 (2008) 59-68.

[24] J. Wang, X. Zhou, P.L. Bradley, S-F. Chang, N. Perrimon, S.T.C. Wong, Cellular phenotype recognition for high-content RNA interference genome-wide screening, J. Biomol. Screen 13 (2008) 29-39.

[25] C. Bakal, J. Aach, G. Church, N. Perrimon, Quantitative morphological signatures define local signaling networks regulating cell morphology, Science 316 (2007) 1753-1756.

[26] S.N. Talapatra, S. Dasgupta, G. Guha, M. Auddy, A. Mukhopadhyay, Therapeutic efficacies of Coriandrum sativum aqueous extract against metronidazole-induced genotoxicity in Channa punctatus peripheral erythrocytes, Food Chem. Toxicol. 48 (12) (2010) 3458-3461.

[27] K. Rodenacker, E.A. Bengtsson, Feature set for cytometry on digitized microscopic images, Anal. Cell. Pathol. 25 (2003) 1-36.

[28] R.M. Haralick, K. Shanmuga, I. Dinstein, Textural features for image classification, Ieee T Syst Man Cyb SMC3 (1973) 610-621.

[29] D. Gabor, Theory of communication, J. Institute Electrical Engineers 93 (1946) 429-441.

[30] M.R. Turner, Texture discrimination by Gabor functions, Biol. Cybern. 55 (1986) 71-82.

[31] D. Zhang, G. Lu, Improving retrieval performance of zernike moment descriptor on affined shapes, IEEE Int. Conf. on Multimedia and Expo 1 (2002) 205-208.

[32] D.B. Wheeler, S.N. Bailey, D.A. Guertin, A.E. Carpenter, C.O. Higgins, D.M. Sabatini, RNAi living-cell microarrays for loss-of-function screens in Drosophila melanogaster cells, Nat. Methods 1 (2004) 127-132.

[33] S.N. Bailey, S.M. Ali, A.E. Carpenter, C.O. Higgins, D.M. Sabatini, Microarrays of lentiviruses for gene function screens in immortalized and primary cells, Nat. Methods 3 (2006) 117-122. 
[34] L.E. Cowen, A.E. Carpenter, O. Matangkasombut, G.R. Fink, S. Lindquist, Genetic architecture of Hsp90-dependent drug resistance, Eukaryot. Cell 5 (12) (2006) 2184-2188.

[35] A.E. Baltus, D.B. Menke, Y.C. Hu, M.L. Goodheart, A.E. Carpenter, D.G. de Rooij, D.C. Page, In germ cells of mouse embryonic ovaries, the decision to enter meiosis precedes premeiotic DNA replication, Nat. Genet. 38 (12) (2006) 1430-1434.

[36] A. Sigal, R. Milo, A. Cohen, N. Geva-Zatorsky, Y. Klein, I. Alaluf, N. Swerdlin, N. Perzov, T. Danon, Y. Liron, T. Raveh, A.E. Carpenter, G. Lahav, U. Alon, Dynamic proteomics in individual human cells uncovers widespread cell-cycle dependence of nuclear proteins, Nat. Methods 3 (2006) $525-531$.

[37] A. Khotanzad, Y.H. Hong, Invariant image recognition by zernike moments, IEEE, 12 (5) (1990) 489-497.

[38] T. Suk, J. Flusser, B. Zitova, Moments and moment invariants in pattern recognition, Wiley and Sons Ltd (2009).

[39] M. Vorobyov, Shape classification using zernike moments, iCamp at University of California Irvine August 5 (2011). 